\title{
XXII. On the composition of caffein, and of some its compounds
}

\section{Edward Chambers Nicholson Esq.}

To cite this article: Edward Chambers Nicholson Esq. (1847) XXII. On the composition of caffein, and of some its compounds, Philosophical Magazine Series 3, 31:206, 115-123, DOI: $10.1080 / 14786444708645799$

To link to this article: http://dx.doi.org/10.1080/14786444708645799

册 Published online: 30 Apr 2009.

Submit your article to this journal

Џll Article views: 3

Q View related articles $₫$ 
to ascertain how far the mechanical equivalent of heat, as determined by my recent experiments on the friction of fluids, might be able to contribute to clear up this question.

The capacity of air at constant pressure, according to the experiments of De la Roche and Berard, is 0.2669 . Consequently a quantity of heat capable of increasing the temperature of a lb. of water by $1^{\circ}$, will give $1^{\circ}$ also to $3.747 \mathrm{lbs}$. of air, while the air will be expanded $\frac{1}{9} \frac{1}{9}$; an expansion in which a force equal to $200^{\circ} 7 \mathrm{lbs}$. through a foot is expended in raising the atmosphere of the earth. The equivalent of a degree of heat per lb. of water, determined by the careful experiments brought before the British Association at Oxford, is $775 \mathrm{lbs}$. through a foot. Hence $200.7 \mathrm{lbs}$. through a foot is equal to $0^{\circ} .259$.

We see, therefore, that for every degree of heat employed by De la Roche and Berard in expanding and heating air, $0^{\circ} .259$ was occupied in producing the mechanical effect, leaving $0^{\circ} \cdot 741$ as that actually employed in raising the temperature of the air. Hence the actual specific heat (commonly called capacity at constant volume) is $0.2669 \times 0.741=0.1977$. Taking this as the specific heat of air and the equivalent 775 , it follows that if a volume of air of $171 \cdot 6$ cubic inches be compressed to $170^{\circ} 6$ cubic inches, it will be heated $1^{\circ}$, a quantity of heat which will occasion an increased pressure of $\frac{1}{49}$. So that the celerity of sound will be increased by this means in the subduplicate ratio of 491 to $661^{\circ} 6$, or in the simple ratio of 2216 to 2572 , which will bring it up from Newton's estimate of 943 to 1095 feet per ", which is as near 1130 , the actual velocity at $32^{\circ}$, as could be expected from the nature of the experiments on the specific heat of air, and fully confirms the theory of Laplace.

Oak Field, near Manchester, July 17,1847 .

XXII. On the Composition of Caffein, and of some of its Compounds. By Edward Chambers Nicholson, Esq.*

CAFFEIN was first analysed by Professors Liebig and

Pfaff $\dagger$ in 1832. The result of this investigation was confirmed by a subsequent analysis of Prof. Wöhler $t$.

In 1838 Professor Liebig induced M. Jobst $\S$ to analyse thein, who proved this body to be identical with caffein. His analyses gave the same results as his predecessors. The same remark applies to the experiments of Mulder || on thein,

* Communicated by the Chemical Society; having been read Feb. 15, 1847.

+ Liebig's Annalen, i. 17.
|| Bulletin des Sciences Phys. et Nat. de Neerlande. 1838, p. 32. 


\section{Mr. Nicholson on the Composition of Caffein,}

and also to an analysis which M. Martius * made of guaranin, a substance, the identity of which with caffein and thein had previously been pointed out by Berthemot and Dechastelus $\dagger$. Lately Dr. Stenhouse f, when examining Paraguay tea, has also made some analyses of thein.

The following table, in which I have recalculated these analyses according to the atomic weights, carbon 6 and hydrogen 1, allows a comparison to be made of the results obtained by these chemists.

Mean of the Analyses.

\begin{tabular}{|c|c|c|c|c|c|c|}
\hline \multirow[b]{2}{*}{ arl } & \multicolumn{2}{|c|}{ Caffein. } & \multicolumn{3}{|c|}{ Thein. } & \multirow{2}{*}{$\begin{array}{c}\text { Guaranin. } \\
\text { Martius. } \\
49 \cdot 23\end{array}$} \\
\hline & & & $\begin{array}{l}\text { Mulder. } \\
49 \cdot 18\end{array}$ & $\begin{array}{l}\text { Jobst. } \\
49 \cdot 47\end{array}$ & $\begin{array}{c}\text { Stenhouse. } \\
48 \cdot 95\end{array}$ & \\
\hline & $5 \cdot 22$ & 5.43 & $5 \cdot 49$ & $5 \cdot 20$ & $5 \cdot 15$ & 5.08 \\
\hline & $28 \cdot 86$ & & $28 \cdot 53$ & $28 \cdot 90$ & & $28 \cdot 83$ \\
\hline
\end{tabular}

The most simple expression which can be deduced from these numbers is

$$
\mathrm{C}_{8} \mathrm{H}_{5} \mathrm{~N}_{2} \mathrm{O}_{2}
$$

Stenhouse's analysis however of the platinum compound proves that this formula must be doubled, and that the atom of caffein or thein is

$$
\mathrm{C}_{16} \mathrm{H}_{10} \mathrm{~N}_{4} \mathrm{O}_{4} \text {. }
$$

The theoretical numbers of this formula are the following:-

$$
\begin{aligned}
& 16 \text { eqs. Carbon . . . } 96 \quad 49 \cdot 48 \\
& 10 \ldots \text { Hydrogen . . } 10 \quad 5 \cdot 15 \\
& 4 \text {... Nitrogen . . } 56 \quad 28 \cdot 86 \\
& 4 \text {... Oxygen . • • } \frac{32}{104} \frac{16.51}{100 \cdot 00}
\end{aligned}
$$

From these numerous experiments the composition of caffein might have been considered as perfectly established. In a recent investigation of coffee, however, M. Payen $\$$ states that he has obtained results which differ very sensibly from those obtained by his predecessors, and which he has translated into the formula

$$
\mathrm{C}_{16} \mathrm{H}_{10} \mathrm{~N}_{4} \mathrm{O}_{3}
$$

which contains 1 equiv. of oxygen less than the formula up. to the present time admitted.

The theoretical numbers of Payen's formula are-

$$
\begin{aligned}
& 16 \text { eqs. Carbon . . . } 96 \quad 51 \cdot 43 \\
& 10 \ldots \text { Hydrogen . . } 10 \quad 5 \cdot 35 \\
& 4 \text {... Nitrogen . . } 56 \quad 30 \cdot 34 \\
& 3 \text {... Oxygen - . } \frac{24}{186} \frac{12 \cdot 88}{100 \cdot 00}
\end{aligned}
$$

- Liebig's Annalen, xxxvi. 93. + Ibid. xxxvi. 90.

t Mem. Chem. Soc., vol. i. pp. 215, 237. [Phil. Mag., xxiii. p. 426.]

Comptes Rendus de l'Académie, tome xxiii. 8. 
We observe here a difference of 2 per cent. of carbon, which M. Payen has obtained over the results of the above-mentioned chemists.

In order to elucidate this discrepancy, Dr. Hofmann induced me to make some experiments under his direction, partly with a quantity of beautiful caffein which he gave me* and partly with a specimen which I have prepared myself.

\section{Caffein.}

To ensure perfect purity of the substance it was crystallized three times from dilute alcohol, washed and dried. Thus purified, it formed very beautiful long white prisms, perfectly transparent when dried in the air, but which became opake if exposed to a higher temperature. The crystals dried in the water-bath lost no weight when kept in an air-bath for four hours at a temperature of $130^{\circ} \mathrm{C}$.

The specimen which I had prepared myself was obtained from Costa Rico coffee, by boiling the bruised fruit in water, precipitating the decoctions by basic acetate of lead and treating the filtrate with hydrosulphuric acid; after the whole of the lead had been removed, I evaporated the liquid to dryness in a water-bath, in order to get rid of acetic acid, and dissolved the residue in a small quantity of boiling water : upon cooling, the caffein crystallized out of a dark colour, and very impure. To purify it, it was washed and recrystallized three times from water, and finally from alcohol. It was then perfectly white, and had exactly the same appearance as the specimen which I obtained from Dr. Hofmann.

\section{Analysis.}

I. $0.3827 \mathrm{grm}$. of substance, dried at $100^{\circ} \mathrm{C}$. and burnt with chromate of lead, gave $0 \cdot 6948$ grm. of carbonic acid, and $0.1800 \mathrm{grm}$. of water.

II. 0.417 grm. of substance, burnt with chromate of lead and chlorate of potash, gave $0.7552 \mathrm{grm}$. of carbonic acid, and $0 \cdot 1965 \mathrm{grm}$. of water.

III. 0.3934 grm. of substance of my own preparation gave $0.7123 \mathrm{grm}$. of carbonic acid and $0.1878 \mathrm{grm}$. of water, which calculated in 100 parts gives-

\begin{tabular}{|c|c|c|c|}
\hline 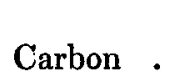 & $\begin{array}{c}\text { I. } \\
\text {. } \quad 49.51\end{array}$ & $\begin{array}{c}\text { II. } \\
49 \cdot 39\end{array}$ & $\begin{array}{l}\text { III. } \\
49 \cdot 37\end{array}$ \\
\hline Hydrogen & $5 \cdot 22$ & $5 \cdot 23$ & $5 \cdot 3$ \\
\hline
\end{tabular}

* I owe this specimen, of great beauty, to the well-known kindness of Mr. E. Merck of Darmstadt.-A. W. H. 
which agrees with Professor Liebig's formula, as is seen by the following:-

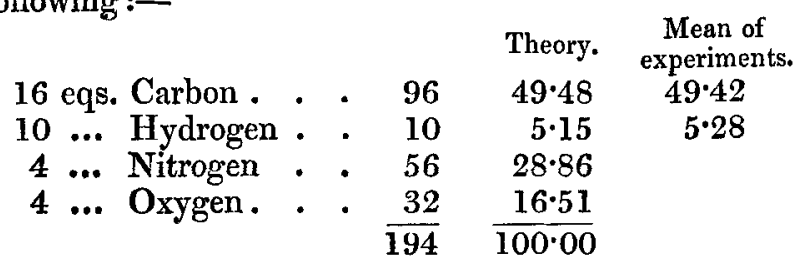

\section{Caffein and Bichloride of Platinum.}

On precipitating a solution of caffein in hydrochloric acid with bichloride of platinum, as Dr. Stenhouse has shown, a precipitate of an orange-yellow colour is obtained. If the two solutions are mixed hot, the fluid on cooling deposits the compound in beautiful granular crystalline tufts, which, when thrown on a filter and washed with alcohol, are perfectly pure. This double salt is only sparingly soluble in alcohol, ather, and water. It does not alter when exposed to light, nor does it lose in weight when kept at $100^{\circ} \mathrm{C}$. for a considerable time.

The analyses of salts, all prepared at different periods and dried at $100^{\circ} \mathrm{C}$., gave the following results :-

I. $0.5382 \mathrm{grm}$. of substance, burnt with chromate of lead, gave $0.4765 \mathrm{grm}$. of carbonic acid, and $0.1387 \mathrm{grm}$. of water.

II. $0.4881 \mathrm{grm}$. of substance gave $0.1196 \mathrm{grm}$, of platinum.

III. $0.4779 \mathrm{grm}$. of substance gave $0.1172 \mathrm{grm}$. of platinum.

IV. $0.6022 \mathrm{grm}$. of substance gave $0.1482 \mathrm{grm}$. of platinum.

V. 0.5781 grm. of substance gave 0.1425 grm. of platinum.

VI. 0.5246 grm. of substance gave 0.1293 grm. of platinum.

VII. $0.3847 \mathrm{grm}$. of substance made of caffein of my own preparation, gave $0.0945 \mathrm{grm}$. of platinum.

Which give the following per-centages:-

Carbon . 23:80

I. II. III. IV. V. VI. VII.

Hydrogen $2 \cdot 86$

$\begin{array}{lllllll}\text { Platinum } \quad \ldots & 24 \cdot 51 & 24 \cdot 52 & 24 \cdot 60 & 24 \cdot 64 & 24 \cdot 64 & 24 \cdot 56\end{array}$ leading exactly to the formula given by Dr. Stenhouse, viz.

$$
\mathrm{C}_{16} \mathrm{H}_{10} \mathrm{~N}_{4} \mathrm{O}_{4} \mathrm{HCl}, \mathrm{Pt} \mathrm{Cl}_{2} \text {, }
$$

as is seen when placed in comparison with the calculated numbers. 


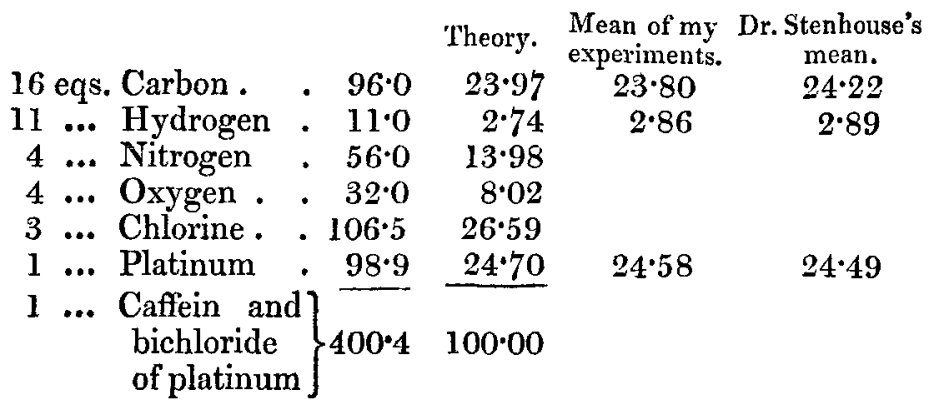

The analysis of caffein, as well as that of the platinum compounds, agree so perfectly with the numbers of Professor Liebig's formula, that there can be no doubt about its accuracy.

Assuming 1 equiv. of oxygen less in the equivalent of caffein, as is proposed by M. Payen, the platinum compound should contain not less than $24 \cdot 46$ per cent. of carbon and $25 \cdot 12$ of platinum. Now three determinations by Dr. Stenhouse, and six which I have made, never gave more than $24 \cdot 64$ per cent., that is, $0 \cdot 6$ per cent. less of platinum.

Not satisfied, however, with these proofs, I have tried to find some other compounds by which the atomic weight of caffein could be determined with equal accuracy.

In what follows a description of several new double salts of caffein will be given, the analyses of which correspond equally well with the original formula of this substance.

\section{Caffein and Nitrate of Silver.}

This compound is obtained when a solution of nitrate of silver is added in excess to an aqueous or alcoholic solution of caffein. If the solutions are concentrated it falls down in white hemispherical nodules, which adhere firmly to the side of the vessel.

When washed with water and crystallized from alcohol it is absolutely pure. This compound is indistinctly crystalline, of a perfectly white colour, and if dry undergoes no change when exposed to light, but if moist acquires a purplish hue. It is very soluble in hot water and alcohol, sparingly soluble in cold, and may be boiled in either solvent without undergoing decomposition. It loses no weight in the water-bath, but at a higher temperature it is decomposed, caffein sublimes, and metallic silver is left.

Analysis.-When burnt with chromate of lead-

1. $0.4514 \mathrm{grm}$. of substance gave $0.4345 \mathrm{grm}$. of carbonic acid, and $0.1162 \mathrm{grm}$. of water. 
II. $0.2500 \mathrm{grm}$. of substance gave $\cdot 0744 \mathrm{grm}$. of silver.

III. $0.2716 \mathrm{grm}$. of substance gave $0810 \mathrm{grm}$. of silver, which give the following per-centages :-

I. II. II.

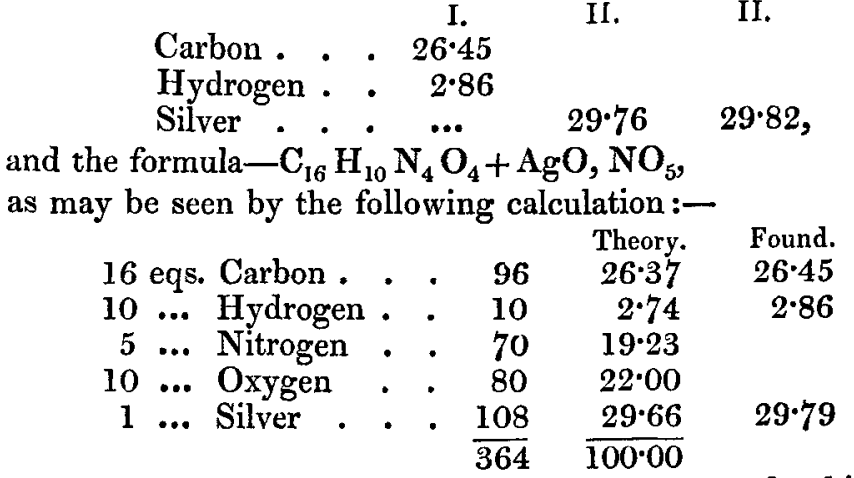

The only analogues to this singular compound which I know are those of urea and nitrate of silver, analysed by Werther*: the formulæ of which are- $\mathrm{C}_{2} \mathrm{H}_{4} \mathrm{~N}_{2} \mathrm{O}_{2}+\mathrm{Ag} \mathrm{O}, \mathrm{NO}_{5}$, and $\mathrm{C}_{2} \mathrm{H}_{4} \mathrm{~N}_{2} \mathrm{O}_{2}+2\left(\mathrm{AgO}, \mathrm{NO}_{5}\right)$.

These compounds, however, in consequence of the peculiar nature of urea, are not very stable, being decomposed when boiled with water into nitrate of ammonia and cyanate of silver. There likewise exists a compound of nitrate of silver and glycocoll, lately described by Horsford $t$, having the formula

$$
\mathrm{C}_{4} \mathrm{H}_{4} \mathrm{NO}_{3}+\mathrm{AgO}, \mathrm{NO}_{5}
$$

and, according to $\mathrm{H}$. Rose, a compound of nitrate of silver with ammonia, 3 equivs. of this gas being absorbed by 1 equiv. of the former salt.

\section{Chloride of Mercury and Caffein.}

This beautiful compound is obtained when an aqueous or alcoholic solution of caffein is added to a solution of chloride of mercury; the latter being kept in excess, the fluid remains perfectly clear, but after the lapse of a few seconds solidifies into a mass of very small crystals, which when recrystallized from water or alcohol and washed on a filter, are quite pure.

When pure and crystallized from water it is very similar in appearance to caffein, the crystals not being however quite so large. It is very soluble in alcohol and water, hydrochloric, nitric, and oxalic acids, and seems to form with the latter a crystalline compound. It is nearly insoluble in æther. In reference to its constitution, it is distinguished from the dou- 
ble salt of platinum, for in this instance the caffein is in direct combination with the chloride of mercury, and is exactly analogous to the corresponding compounds of leucoline and aniline investigated by Dr. Hofmann*. The mercurial compounds of this kind are generally easily decomposed, but the compound of chloride of mercury and caffein is so stable, that it may be boiled in water for a considerable time without undergoing the slightest change in its properties. It may be dried at $100^{\circ} \mathrm{C}$. and loses no weight at that temperature.

I endeavoured to combine the determination of the carbon, hydrogen and mercury of this substance in one combustion, and have perfectly succeeded. The operation was conducted as follows:- The substance was mixed with chromate of lead and introduced into a combustion-tube of at least 26 inches in length. About 6 inches of copper turnings are placed above the mixture, leaving a space of 8.inches from the copper to the anterior end of the tube. A receptacle for the mercury is formed out of the tube itself by contracting it about an inch from the copper turnings, and again so as to leave an elongated bulb of an inch in length. At the close of the operation the tube is cut with a file at the posterior contraction. In order to separate the water from the mercury, the chloride of calcium tube (which has not been detached) is connected with an aspirator and air admitted through chloride of calcium, the bulb being kept at a temperature of $100^{\circ} \mathrm{C}$.

I obtained in my analysis the following numbers :- 0.7833 grm. of substance gave 0.5832 grm. of carbonic acid, 0.1639 grm. of water, and $0.3365 \mathrm{grm}$. of mercury, corresponding to the following per-centage, which I place in comparison with the theoretical numbers:-

$$
\begin{aligned}
& \text { the theoretical numbers:- Theory. Expt. }
\end{aligned}
$$

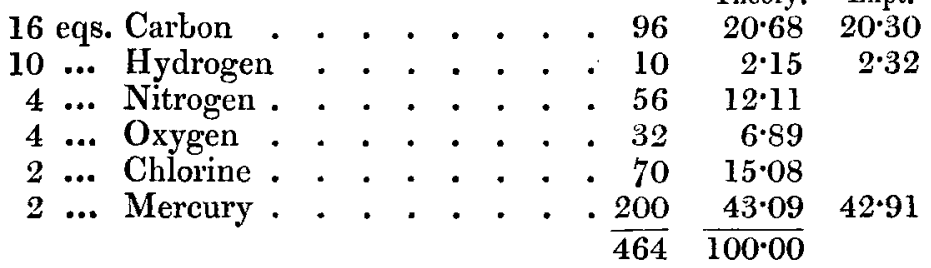

Caffein and Terchloride of Gold.

This compound is formed when a solution of terchloride of gold is added in excess to caffein dissolved in dilute hydrochloric acid. If concentrated solutions are employed, the whole immediately solidifies into a mass of a most splendid lemon-yellow colour; this is to be washed with cold water

* Liebig's Annalen, xlvii. 37. 
and crystallized from alcohol, and finally dried in the waterbath.

The crystals from an alcoholic solution are in the form of long needles, of an orange-yellow colour and a very bitter metallic taste; they are soluble in alcohol and water. When boiled in water for a short time, the salt is decomposed, a yellow flocculent matter precipitating, which is insoluble in alcohol, ether and water, but soluble in hydrochloric acid. If an aqueous solution is kept on the sand-bath for some hours at a temperature of about $68^{\circ} \mathrm{C}$. it is also decomposed, and metallic gold separates in shining scales.

It is not altered when exposed to light, and when dry may be heated to $100^{\circ} \mathrm{C}$. without undergoing decomposition.

Analysis, - When burnt with chromate of lead-

I. $0.8530 \mathrm{grm}$. of substance gave $0.5525 \mathrm{grm}$. of carbonic acid and $0 \cdot 1622 \mathrm{grm}$. of water. gold.

II. $0.3224 \mathrm{grm}$. of substance gave $0.1197 \mathrm{grm}$. of metallic

III. $0.3019 \mathrm{grm}$. of substance gave $0.1115 \mathrm{grm}$. of metallic gold, which give the following per-centages:-

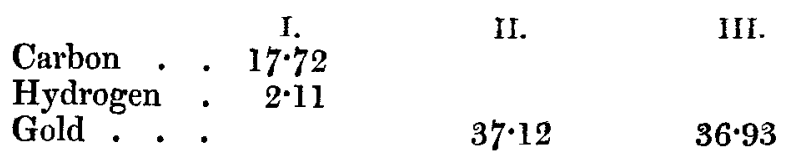

corresponding to the formula $\mathrm{C}_{16} \mathrm{H}_{10} \mathrm{~N}_{4} \mathrm{O}_{4} \mathrm{HCl} \mathrm{Au} \mathrm{Cl}$, as may be seen by the following table, where the calculated and quantities found are placed in comparison:-

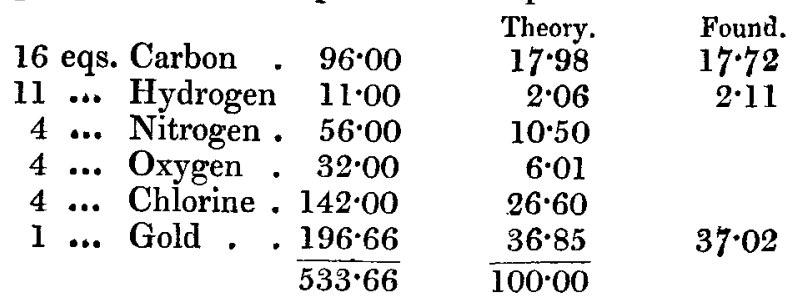
fore-

The caffein compounds which I have analysed are thereCaffein . . . . . $\mathbf{C}_{16} \mathrm{H}_{10} \mathbf{N}_{4} \mathbf{O}_{4}$.

Platinum compound $\mathrm{C}_{16} \mathrm{H}_{10} \mathrm{~N}_{4} \mathrm{O}_{4}, \mathrm{HCl} \mathrm{Pt} \mathrm{Cl} \mathrm{Cl}_{2}$ Silver compound $\mathrm{C}_{16} \mathrm{H}_{10} \mathrm{~N}_{4} \mathrm{O}_{4}, \mathrm{AgO}, \mathrm{NO}_{5}$. Mercury compound $\mathrm{C}_{16} \mathrm{H}_{10} \mathrm{~N}_{4} \mathrm{O}_{4}, 2(\mathrm{Hg} \mathrm{Cl})$. Gold compound . . $\mathrm{C}_{16} \mathrm{H}_{10} \mathrm{~N}_{4} \mathrm{O}_{4} \mathrm{HCl}, \mathrm{Au} \mathrm{Cl}_{3}$.

There exist several other double compounds of caffein, which I have however not subjected to analysis. 
On mixing a hot alcoholic solution of caffein with an alcoholic solution of cyanide of mercury, beautiful needles of a double salt are deposited upon cooling, which correspond most likely to the mercury salt I have just described. A solution of caffein in hydrochloric acid gives a beautiful brown precipitate with chloride of palladium; and the filtered solution deposits another compound in the form of yellow scales, very similar in appearance to iodide of lead.

Caffein gives no precipitate with solutions of sulphate of copper, chloride of tin, acetate of lead, and nitrate of suboxide of mercury. When boiled with sesquichloride of iron, a reddish-brown precipitate subsides upon cooling, which is perfectly soluble in water, and is most likely a double compound of caffein and sesquichloride of iron.

XXIII. Note in reference to the extension of Euler's Theorem. By J. R. Young, Professor of Mathematics in Belfast College.

Dear Sir,

To Richard Taylor, Esq.

TN the Philosophical Magazine for June last a communica1 tion of mine was published respecting an extension of a certain theorem of Euler concerning the products of the sums of squares. At the time that notice was written, I was under the impression that the theorem admitted of an extent of generalization which a further investigation of the matter proves to me has not place. I am now prepared to show that the proposition does not hold beyond the case for eight squares, the formulæ for which I have already printed in the Proceedings of the Royal Irish Academy; in the Transactions of which body it is probable that the entire investigation of the theorem for eight squares, and the proof that it does not apply beyond that number, will hereafter appear.

It may perhaps be interesting to algebraists to find the real limits to this theorem demonstrably established; and thus to know-in any attempts that may hereafter be made to extend Sir W. R. Liamilton's remarkable and very fertile theory of quaternions-beyond what boundaries such attempts must prove fruitless.

Belfast, July 16, 1847.

I remain, dear Sir, Very faithfinlly yours, J. R. Young. 